\section{InI)ret}

1.2021

Sandra Camacho Clavijo

Universitat Autònoma de

Barcelona

\title{
La solidaridad con “motivos razonables” o la denominada gestión de asuntos ajenos del Libro Sexto del Código Civil de Cataluña.
}

\begin{abstract}
Sumario
En la coyuntura actual de crisis del Estado del bienestar, figuras como la gestión de asuntos ajenos, se revelan aptas como medio de canalizar el auxilio puntual prestado por los particulares. La revisión de esta institución en el Libro Sexto del Código Civil de Cataluña parte de superar la desfavorable configuración de este tipo de gestión como acto de injerencia, consecuencia del dogma de la autonomía de voluntad y promoverla como vía de ejercicio de la solidaridad. El artículo 62240 CCC tipifica como requisito de existencia de la gestión de negocios ajenos que la actuación deba realizarse con cualquier "motivo razonable" y en consecuencia toda gestión no justificada no podrá ser calificada como gestión de negocios ajenos ni activará las reglas de indemnización que actúan en esta institución. Como el CCC no regula de forma expresa un criterio para determinar cuándo concurren un "motivo razonable" el objeto de este trabajo es resolver esta cuestión para lo que nos hemos servido de los principios y definiciones de los textos de armonización del Derecho Privado europeo que han servido de inspiración al legislador catalán.
\end{abstract}

\begin{abstract}
In the current situation of the welfare state crisis, figures such as the benevolent interventions in another's affairs, are shown to be suitable as a means of channelling the punctual assistance provided by individuals. The revision of this institution in the Sixth Book of the Civil Code of Catalonia is based on overcoming the unfavourable configuration of this type of intervention as an act of interference, a consequence of the dogma of autonomy of will and promoting it as a way of exercising solidarity. Article 622-40 CCC typifies as a requirement for the existence of the benevolent intervention in another's affairs, that the action must be carried out for any "reasonable grounds" and consequently any unjustified action cannot be classified as benevolent intervention in another's affairs nor will it activate the compensation rules that act in this institution. As the CCC does not expressly regulate a criterion to determine when "reasonable grounds" concur, the purpose of this work is to resolve this issue. We have used the principles and definitions of the harmonization texts of European Private Law that have inspirited to the Catalan legislator to resolve it.
\end{abstract}

Title: Solidarity with "reasonable grounds" or the so-called benevolent intervention in another's affairs of the Sixth Book of the Civil Code of Catalonia.

Palabras clave: Gestión de asuntos ajenos, solidaridad intrafamiliar, motivo razonable, enriquecimiento injustificado, ratificación, resarcimiento e indemnización Keywords: Benevolent intervention in another's affairs, intra-family solidarity, reasonable ground, unjustified enrichment, ratification, redress, compensation

DOI: $10.31009 /$ InDret.2021.i1.03 
InI)ret

1.2021

Recepción

$25 / 08 / 2020$

Aceptación

20/10/2020
Índice

1. Introducción: hacia la actualización de la figura de la gestión de negocios ajenos

2. La gestión de asuntos ajenos: concepto y naturaleza jurídica.

3. La gestión como elemento delimitador de la existencia de la figura

3.1.El alcance de la gestión: La gestión de un asunto material o jurídico. 3.2.La gestión de "un asunto ajeno, con motivo razonable y sin un encargo ni una obligación previa”

a. La gestión espontánea de un asunto ajeno

b.La gestión con motivos razonables: el modelo del Derecho Civil catalán

c.La actuación del gestor en interés general a modo de "motivo razonable" implícito

d.La actuación del gestor no oficiosa: un supuesto de enriquecimiento injustificado

4. Consecuencias de la calificación de la actuación como gestión de asunto ajeno: breve análisis.

5. El conocimiento de la gestión oficiosa por el dueño

6. Bibliografía

Este trabajo se publica con una licencia Creative Commons Reconocimiento-

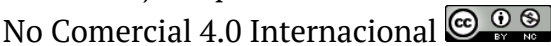




\section{Introducción: hacia la actualización de la figura de la gestión de negocios ajenos*.}

En la coyuntura actual de desmantelamiento del Estado del bienestar la asistencia pública necesaria de apoyo a las personas que necesitan ayuda (por ej. por padecer algún tipo de discapacidad) no está garantizada ${ }^{1}$. En consecuencia, se hace necesario el estudio de figuras, como la gestión de negocios ajenos, que se revelan aptas para canalizar el auxilio puntual prestado por los particulares. La revisión de esta institución parte de superar la desfavorable configuración de este tipo de gestión como acto de injerencia, consecuencia del dogma de la autonomía de voluntad ${ }^{2}$ y promoverla como vía de ejercicio de la solidaridad.

En efecto, ante la fuerza del principio general y fundamental de Derecho Privado de no injerencia (principio considerado de orden público ya que nadie puede injerir en la esfera jurídica de la persona sin autorización del interesado o de la ley) ${ }^{3}$, la prevalencia del carácter ético de esta figura, de su configuración como vehículo jurídico de la ayuda al prójimo, la transforma en una institución aplicable en la realidad social actual ${ }^{4}$. La finalidad social de esta figura ha sido advertida por el propio legislador catalán que significa en el Preámbulo de la Ley 3/2017 de 15 de febrero del Libro sexto del Código Civil de Cataluña relativo a las obligaciones y contratos (BOE $\mathrm{n}^{\circ} 57$ de 8.3.2017) (en adelante CCC) que la gestión se asuntos ajenos "se configura como un

\footnotetext{
* Este trabajo tiene su origen en el desarrollo de una parte del proyecto "El Derecho Civil catalán inclusivo: hacia un nuevo modelo de discapacidad mental. La innovación tecnológica y la solidaridad como sistema de apoyo del ejercicio de la capacidad natural", Premio Ferrer Eguizábal 2019 al mejor proyecto de investigación sobre Derecho Civil catalán.

${ }^{1}$ Según los datos emitidos por la Asociación Estatal de Directoras y Gerentes en servicios sociales, a fecha 31 de diciembre de 2019 había en España 1.385.037 personas en situación de dependencia reconocida y otras 159.193 pendientes de valoración. Esto significa que el 3\% de la población española necesita apoyos de mayor o menor intensidad para desarrollar las actividades básicas de la vida diaria. Durante 2019, por primera vez desde 2016, el número de personas con derecho reconocido en espera de atención ha vuelto a aumentar. El saldo de 2019 presenta 20.000 personas más en una lista de espera, que ya alcanza a 266.000 personas, el 19,2\% de las personas con derecho.
}

A ellos hay que añadir 160.000 expedientes -personas-que están pendientes de valoración. Son 30.000 más que hace un año. Con lo cual, la desatención (pendientes de valorar + limbo) alcanza a 426.000 personas (50.000 más que a final de 2018). Durante 2019 fallecieron sin haber podido ejercer sus derechos derivados de la condición de persona en situación de dependencia 31.000 personas. Esto supone que diariamente fallecen más de 85 personas dependientes sin haber llegado a recibir prestaciones o servicios. Ver XX Dictamen del Observatorio de la Ley 39/2006 de promoción de la autonomía personal y atención a las personas en situación de dependencia (https://www.directoressociales.com/images/documentos/dictamenes/XX_Dictamen/INFO\%20GLOBAL\%2 OXX\%20DICTAMEN\%203-3-20 compressed.pdf).

${ }^{2}$ Sólo el titular de un bien puede usar, gozar y disponer de él de modo que mejor entienda conduce a considerar ilícita cualquier actuación en los negocios de otro. Ver Digesto, De regulis Iuris, L.50, Tit. 17, 36: "Es culpa inmiscuirse uno en cosa que no le pertenece" en GARCIA DeL CoRRAL, Ildefonso L.; Cuerpo del Derecho Civil Romano, T.III, Barcelona, 1897, reimpresión en Lex Nova, Valladolid, 2004, p.947.

${ }^{3}$ Ver BetTi, Emilio; Teoría General de negocio jurídico, Editorial Revista de Derecho Privado, Madrid, 1959, p. 39, De Castro Y Bravo, Federico; El negocio jurídico, Civitas, Madrid, 1985, p. 12 y ss, Rivero Hernández, Francisco; Representación sin poder y ratificación, Civitas Thomson, Navarra, 2013, p. 45.

${ }^{4}$ Muchos son los autores que destacan este carácter ético de la institución entre otros PasQuau Liaño, Miguel; La gestión de negocios ajenos, Montecorvo, Madrid, 1986, p.37, Puig PeÑA, Federico, Compendio de Derecho Civil Español, T. IV, Aranzadi, Pamplona, 1972, p. 537, SÁnchez RomáN, Felipe, Estudios de Derecho Civil, Madrid, T.IV, Tipográfico Sucesores de Rivadeneyra, Madrid, 1899, p.999 que destaca que "debemos hacer a otros todo lo que quisiéramos hicieran por nosotros en iguales circunstancias". 
instrumento de solidaridad o auxilio mutuo entre particulares, lejos, sin embargo, de todo acto de injerencia indebida" y añade "Es una gestión desinteresada con el propósito de atender un asunto ajeno en interés o utilidad de su titular y no se fundamenta ni debe confundirse con el ánimo de liberalidad, el cual no puede presumirse."

En este mismo sentido, el Proyecto Académico Marco Común de Referencia para el Derecho Contractual europeo (en adelante DCFR), exponente de los trabajos de armonización del Derecho privado europeo, la concibe como instrumento de fomento de la solidaridad social ${ }^{5}$. Así, en el apartado 18 de la introducción del Principles, Definitions and Model Rules of European Private Law Draft Common Frame of Reference (DCFR) se dice que el principio de solidaridad y responsabilidad social se refleja de forma relevante en figuras como la gestión de negocios ajenos: "However, the promotion of solidarity and social responsibility is not absent from the private law rules in the DCFR. In the contractual context the word "solidarity" is often used to mean loyalty or security. It is of great importance to the DCFR. The principle of solidarity and social responsibility is also strongly reflected, for example, in the rules on benevolent intervention in another's affairs, which try to minimise disincentives to acting out of neighbourly solidarity".

\section{La gestión de asuntos ajenos: concepto y naturaleza jurídica.}

La gestión de asuntos ajenos es la intervención o actuación por parte de un sujeto (el gestor) en la esfera jurídica ajena, sin previa autorización de su titular. La persona en cuyo favor se realiza la gestión recibe el nombre de "titular del asunto" o titular (arts. 622-42.1 CCC y 622-40.1 CCC). Esta figura ha sido regulada en el Código Civil español (en adelante CC), tradicionalmente llamada gestión de negocios ajenos (art. 1888 y ss.) y en el Libro Sexto del CCC que le dedica tres artículos (art. 622-40, 622-41 y 622-42) en la sección tercera del Capítulo II titulado Contratos sobre actividad ajena e integrado en el Título II titulado Fuentes contractuales, Contratos en particular. Tanto el art. 1888 CC $^{6}$ como el art. 622-40 del CCC, establecen un concepto de la figura que se delimita partiendo de la descripción de la actividad de la gestión que la caracteriza y de la principal consecuencia para el gestor: continuar la gestión hasta finalizarla o bien requerir al titular para que le sustituya. Así el art. 622-40 CCC, ordena que “La persona que gestiona un asunto ajeno, con motivo razonable y sin un encargo ni una obligación previa, está obligada a continuar la gestión jurídica o material hasta finalizarla o a requerir al titular, al representante o al administrador que lo sustituya en la gestión comenzada". También en este sentido se pronuncia el DCFR que establece como requisitos de existencia de la gestión oficiosa que ésta haya sido realizada por el gestor con un "motivo razonable" o que sea aprobada por el dueño del negocio: "El presente Libro será de aplicación cuando una persona (el gestor) actúe, principalmente con la intención de beneficiar a otra (el dueño del negocio) y: a) el gestor tenga un motivo razonable para actuar; o b) el dueño del negocio apruebe el acto sin una demora injustificada que pudiera perjudicar al gestor" (V-1:101) .

\footnotetext{
${ }^{5}$ Disponible en (http://ec.europa.eu/justice/policies/civil/docs/dcfr outline edition en.pdf) y su traducción en Jerez Delgado, Carmen (Coord); Principios, definiciones y reglas de un Derecho Civil europeo: el Marco Común de Referencia (DCFR), Agencia estatal Boletín Oficial del Estado, Madrid, 2015, p. 307.

${ }^{6} \mathrm{El}$ art. $1888 \mathrm{CC}$ dice que "El que se encarga voluntariamente de la agencia o administración de los negocios de otro, sin mandato de éste, está obligado a continuar su gestión hasta el término del asunto y sus incidencias, o a requerir al interesado para que le sustituya en la gestión, si se hallase en estado de poder hacerlo por sí".

${ }^{7}$ Ver traducción del artículo V-1-101 en Jerez Delgado, Carmen (Coord); Principios, definiciones y reglas de un Derecho Civil europeo...”, ob.cit p. 307.
} 
Sin embargo, mientras en el CC la figura está regulada en el capítulo I titulado "de los Cuasicontratos" del Título XVI titulado de las obligaciones que se contraen sin convenio (artículos 1888 CC a 1984 CC), y en el CCC se tipifica en los artículos 622-40 a 622-42 que bajo la denominación "gestión de asuntos ajenos sin mandato" integran la Sección tercera del Capítulo II titulado "Contratos sobre actividad ajena” del Título II ("Tipos contractuales”) del Libro VI del CCC; en el DCFR esta figura está comprendida en el Libro V, al margen de los Libros II y IV que regulan la parte general de los contratos y diferentes tipos contractuales.

La ubicación sistemática de la figura en el CCC es fiel reflejo del debate que la doctrina ha venido manteniendo sobre su posible naturaleza jurídica contractual. En la actualidad, la doctrina mayoritaria considera esta institución como una figura autónoma ${ }^{8}$ que es ajena al contrato de mandato, pero también a la cuestionada categoría jurídica del cuasi contrato del CC que se considera ha dejado de ser útil por la heterogeneidad de sus elementos y porque es posible explicarlos recurriendo a las demás fuentes jurídicas9. Con el desvanecimiento de esta categoría, la gestión oficiosa se alza con autonomía propia y es definida como un acto jurídico unilateral no negocial ${ }^{10}$, definición que recoge el propio legislador catalán en el Preámbulo de la ley de aprobación del Libro Sexto del CCC al decir que "las obligaciones derivadas de la gestión de asuntos ajenos, que se basan en un acto voluntario no negocial (...)". Por tanto, lo adecuado, hubiera sido regular esta figura en el código de forma autónoma a los tipos contractuales como ya se había

\footnotetext{
${ }^{8}$ La mayor parte de la doctrina que prescinde de la categoría del cuasicontrato ratifica a su vez la consideración de la gestión de negocios ajenos y del pago de lo indebido como modalidades autónomas,

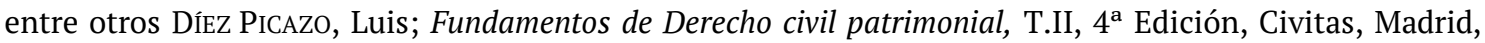
1993, p.149, PASQUAU LiAÑo, Miguel; La gestión..., ob.cit. p.327, SÁNCHEZ JoRDÁn, María Elena; La gestión de negocios ajenos, Civitas, Madrid, 2000, p. 37, MARco Molina, Juana; “La gestión oficiosa de negocios ajenos: el nacimiento autónomo de las obligaciones del gestor y “dominus” o titular del asunto gestionado” en AAVV, Estudios Jurídicos en Homenaje al Profesor José María Miquel, Vol. 1, Thomson Reuters Aranzadi, Navarra, 201, p. 1826, PARra LuCÁN, Mº́ngeles; “Los cuasicontratos” en MARTinez De Aguirre Aldaz, Carlos; Curso de Derecho Civil II-Derecho de Obligaciones, Colex, Madrid, $4^{\mathrm{a}}$ Ed. 2014, p. 832. Por su parte Lacruz Berdejo, José Luís, y SANCho Rebullida, F.A; Elementos de Derecho Civil, T.II, Vol. II, Edición Bosch Barcelona, 1979, p.375 se posición en contra de la categoría del cuasicontrato pero le otorgan cierta utilidad para expresar aquellas obligaciones que proceden, no de la ley, sino de principios generales del Derecho y singularmente la de restituir el enriquecimiento injusto.

${ }^{9}$ Así por ejemplo el cobro o pago de lo indebido se refiere al pago o cumplimiento de obligaciones, el enriquecimiento sin causa en la exposición de las fuentes de obligaciones como una más y la gestión de negocios ajenos como acto jurídico unilateral no negocial.

${ }^{10}$ Existe una discusión sobre si la gestión de negocios ajenos puede ser calificada como hecho o actos jurídicos. La doctrina se posiciona según se defina el acto jurídico unilateral. Para algún autor (MARTIN DE LA Moute, Jacques; L'acte juridique unilateral, Essai sur sa notion et sa technique en Droit Civil, Bernard Ferères, Paris, 1951, p.26) éste requiere que la persona tenga la intención de realizar los efectos de derecho y según esta definición como la actuación del gestor está dirigida no a las consecuencias del acto previstas en la norma jurídica sino al resultado material estaríamos ante un hecho jurídico en el que los resultados producidos intervienen sin que sea necesario que la persona tenga la voluntad de su realización. Para otra parte de la doctrina el hecho se califica de acto jurídico porque el Ordenamiento tiene en consideración la voluntad del hombre, entonces se califica la gestión de negocios ajenos como acto jurídico. Esta postura es la mayoritaria, PASQuAu Liaño, Miguel; La gestión...., ob.cit.p.337, NuÑEz LAGos, Rafael; Código Civil Comentado y concordado extensamente, de Quintus Mucius Scaevola, T.XXX, vol. 2, (arts 1887 a 1901), Reus, Madrid, 1961, p.238, CuADRADO IGLESIAS; Manuel; “Configuración, fundamento y naturaleza de la gestión oficiosa de negocios ajenos” en CuAdRADo IGLESIAS, Manuel/NúÑEz BoludA, María de los Desamparados (Dir), Estudios Jurídicos en Homenaje al profesor Manuel García Amigo, T.I, La Ley, Madrid, 2015, p.726 y BETTI, Emilio; Teoría General del negocio jurídico.., ob.cit., p.125 y ss, quien incluso considera que puede entenderse que es negocio jurídico unilateral si éste se define como conducta que responde a una función económicosocial típica tutelada por ley.
} 
hecho en los precedentes legislativos ${ }^{11}$. Entendemos que la ubicación de esta figura fuera del esquema tanto contractual como cuasicontractual precisamente hubiera facilitado su exclusión de la tendencia doctrinal a considerarla como una fuente unitaria de obligaciones, lo cual no es cierto ya que las obligaciones del gestor y del dominus proceden de fuentes independientes.

a) Las obligaciones que son a cargo del gestor (el deber de continuar la gestión hasta la conclusión del asunto y de atenderlo con diligencia) son consecuencia de su conducta, de su actuación. El gestor oficioso no se obliga en virtud de una declaración de voluntad expresa o tácita (de querer gestionar), sino porque desempeña un acto de efectiva gestión. Se obliga ex negotio gesto. En este sentido se expresa el Preámbulo del Libro Sexto del CCC que expresamente reconoce que es un acto voluntario no negocial e indica que "los efectos jurídicos son independientes de la intención o voluntad subyacente en la conducta del gestor, sino, además, porque el gestor no se obliga a partir de una declaración de voluntad, sino por el mismo acto de gestión". La gestión no constituye un negocio ya que el gestor actúa, sin querer ni obligarse ni ser resarcido, pero, al margen de esta voluntad, la ley reconoce efectos a su actuación. Se trata de un acto jurídico en sentido estricto.

b) Mientras que, las obligaciones del "dueño" (principalmente el deber de resarcimiento) se fundamentan bien en su propia voluntad, con la ratificación expresa o tácita de lo actuado, bien en la ley cuando, como veremos, la gestión se considere justificada ${ }^{12}$.

Sin duda el hecho de que la gestión de asuntos ajenos que surge de un acto espontáneo unilateral acabe desembocando en un mandato, cuando el titular ratifique la gestión realizada (art 622-40.2 CCC) puede ser la causa de que el legislador catalán haya incluido su regulación en el ámbito de los contratos ${ }^{13}$. Y así parece justificarse el legislador catalán en el mismo Preámbulo de la Ley de

\footnotetext{
${ }^{11}$ En efecto, en los trabajos preparatorios de l'Observatori de Dret Privat de la Conselleria de Justícia de Catalunya de 2004 (Secció de Dret Patrimonial) se regulaba la gestión oficiosa en sede de actos lícitos y voluntarios que hacen nacer las obligaciones, sección $1^{\mathrm{a}}$ del Capítulo II, Las fuentes de la Obligación, del Título I sobre la obligación (art 612-2), Ver Treballs preparatoris del llibre sisè del Codi Civil de Catalunya: les obligacions i els contractes. Departament de Justícia, Generalitat de Catalunya (23-04-2004), p.84. Sin embargo el Avantprojecte de 23 de febrer de 2016 no reguló la figura al no contener regulación el Capítulo II, posteriormente se introducen mediante enmienda de adición presentada por el Grupo "Junts pel sí” (esmena 11) y entran a formar parte sin ningún tipo de modificación ni enmienda (Ver tramitación en (BOPC núm $72 \quad$ https://www.parlament.cat/document/bopc/165863 y $\quad$ BOPC núm. 239 https://www.parlament.cat/document/bopc/178930). Ver estudio en DE BARRÓN ARNICHES, Paloma; “Gestión de asuntos ajenos sin mandato. Breve apunte sobre los problemas prácticos que se derivan de la nueva regulación” en SERRANo De NiCOLÁs, Ángel (Coord); Estudios sobre el Libro Sexto del Código Civil de Cataluña, Colegio Notarial de Cataluña/Marcial Pons, Madrid, 2018, p. 368.

${ }^{12}$ En este sentido Marco MolinA, Juana; “La gestión oficiosa...ob.cit. p. 1824 y 1826.

${ }^{13}$ En este sentido también parece expresarse DE BARRÓN ARNICHES, Paloma; "Gestión de asuntos ajenos sin mandato...”, ob.cit. p. 369 cuándo se pregunta el porqué del cambio de orientación del legislador catalán. Sin embargo, no compartimos su argumentación, ya que entendemos que la consecuencia del desvanecimiento de la categoría del cuasicontrato no es que la gestión oficiosa sea considerada figura residual de contrato de mandato, sino que se le atribuya carácter autónomo y se la considere acto jurídico unilateral no negocial.
} 
aprobación del Libro Sexto del CCC ${ }^{14}$ cuándo le atribuye a la figura carácter de mandato residual y centra su mayor preocupación en establecer las reglas para aquellos supuestos en los que no exista una ratificación del titular del asunto y así el legislador finaliza diciendo: "En definitiva, se quiere delimitar el ámbito de la gestión de asuntos ajenos, cuando no sean de aplicación las reglas del contrato de mandato". En suma, este trabajo tiene por objeto delimitar en qué casos la actuación del gestor al no ser ratificada por el dueño queda fuera del contrato de mandato y se erige como gestión de asuntos ajenos cuya autonomía radica en la aplicación de su propia normativa. Veamos pues cuales son los presupuestos previstos en el CCC de existencia de esta figura.

\section{La gestión como elemento delimitador de la existencia de la figura}

La primera cuestión que analizaremos es cuándo existe una actuación que constituya una gestión de asuntos ajenos que en adelante también denominaremos gestión oficiosa. Como ya se ha advertido la gestión de asuntos ajenos es una excepcionalidad del principio de no injerencia ya que cualquier intervención en la esfera de otra persona debe producirse con su consentimiento. Sin embargo, el Ordenamiento Jurídico, en el caso de auxilio prestado por el particular a un tercero, despoja de su carácter antijurídico a dicha intromisión siempre que se cumplan ciertos requisitos ya que de conformidad con el art. 622-40 CCC la actuación deberá consistir en la gestión de "un asunto ajeno, con motivo razonable y sin un encargo ni una obligación previa".

\subsection{El alcance de la gestión: La gestión de un asunto material o jurídico.}

La primera cuestión jurídica que se plantea en la delimitación de la gestión es cual deberá ser el alcance de la gestión. La ayuda espontánea del particular al titular no sólo consistirá en la realización de actos jurídicos sino también de actos materiales por lo que se cuestiona si todas estas tareas quedan comprendidas en la actuación que se puede desempeñar en la gestión oficiosa.

En Derecho Civil español esta cuestión se plantea porque el término "agencia o administración de negocio" del artículo 1888 CC parece circunscribir la gestión a la exclusiva realización de actos jurídicos. Ahora bien, la doctrina propone una interpretación amplia del alcance de este término

\footnotetext{
${ }^{14}$ Preámbulo de la Ley 3/2017, de 15 de febrero, del libro sexto del Código civil de Cataluña, relativo a las obligaciones y los contratos, y de modificación de los libros primero, segundo, tercero, cuarto y quinto. (BOE $n^{\circ} 57$ de 8.3.2017): “A pesar de que es una institución jurídica que, tradicionalmente, se trata en el ámbito de las fuentes no contractuales de las obligaciones, en concreto de las derivadas de hechos y actos lícitos, y que suele incluirse en la definición, también tradicional, de cuasicontrato, la presente regulación se aparta de esta sistemática.

Efectivamente, la gestión de asuntos ajenos se presenta como una institución residual respecto al mandato, precisamente por el hecho de que la ratificación de la gestión supone la aplicación de las reglas del mandato. Ahora bien, a falta de ratificación, es necesario determinar las obligaciones derivadas de la gestión de asuntos ajenos, que se basan en un acto voluntario no negocial, no solo porque los efectos jurídicos son independientes de la intención o voluntad subyacente en la conducta del gestor, sino, además, porque el gestor no se obliga a partir de una declaración de voluntad, sino por el mismo acto de gestión.

Se evidencia que son necesarias unas reglas para el supuesto de hecho de la gestión de asuntos ajenos, centradas fundamentalmente en el deber de diligencia exigible al gestor en función del asunto gestionado, el deber de comunicación y de rendición de cuentas y, sobre todo, su resarcimiento e indemnidad, pero sin ningún derecho de retribución, aunque se trate de un profesional. En definitiva, se quiere delimitar el ámbito de la gestión de asuntos ajenos, cuando no sean de aplicación las reglas del contrato de mandato”
} 
que incluya tanto administración ordinaria, extraordinaria ${ }^{15}$ como la realización de actos jurídicos (compraventa en interés del tercero, pagar una deuda) y actos puramente materiales (ayuda en el aseo, suministro de comida ${ }^{16} . .$. et) que por sí solos no exigen el despliegue de actividad jurídica, aunque en algunos casos puedan producir efectos jurídicos (reparar el tejado del vecino que amenaza con caerse) ${ }^{17}$. Por su parte, la jurisprudencia del TS también se ha pronunciado a favor del reconocimiento de la realización de actos puramente materiales en interés de un tercero como gestión oficiosa.

- Así, la STS 2.04.1929 (Gac Madrid 315) reconoce como gestión el hecho de cuidar a un hermano discapacitado intelectual que comprende tanto actividades de administración de bienes como de atención a sus necesidades personales ${ }^{18}$. En la STS 2.2.1954 (CL 33) se reitera el mismo argumento en relación con el cuidado de un hermano incapaz, aunque en este supuesto el hermano no sólo se hace cargo de los cuidados personales que precisaba como consecuencia de su enfermedad mental (ingresos en régimen sanatorial, familiar, cuidado, vigilancia, vestido del enfermo, alimentación) sino también de la administración patrimonial de sus bienes. Este carácter patrimonial de la actuación es destacado por la sentencia para ratificar la calificación de la actuación como de gestión de negocios ajenos: “dados los hechos que se tienen por ciertos en la sentencia discutida, que revelan cumplidamente que el demandado no se limitó a cuidar de su hermano incapaz teniéndole unas veces en manicomios y otras en su propia casa, sino que al mismo tiempo administraba sus bienes y esto no de un modo esporádico como se sostiene en el recurso, sino con la continuidad que toda administración lleva consigo, no puede dudarse que al calificar la misma de gestión de negocios ajenos se le ha dado el nombre que legalmente le corresponde

\footnotetext{
${ }^{15}$ Principalmente la doctrina argumenta en este sentido que entender que el gestor no está legitimado para cualquier tipo de administración, tendría consecuencias negativas para el dominus, por tanto se entiende que el gestor está legitimado para realizar actos de administración, disposición, manejo y posesión; Así resulta del propio CC cuyo artículo 1893.2 reconoce que el gestor puede actuar con ocasión de "evitar algún peligro inminente y manifiesto”, aceptando implícitamente la realización de actos que exceden de la mera administración ordinaria. Ver en este sentido en SÁNCHEZ JoRDÁN; María Elena; La gestión...., ob.cit., p.69, FERRARI, Sigfrido, Gestione di affari altrui e rappresentanza, Giuffrè Editore, Milan , 1962, p. 36 y en este sentido Sentencia del TS de 16 de octubre de 1978 (RJ 1978\3076): “Que en definitiva, debe prevalecer la condena a la rendición de cuentas, asentada en el principio general de que allí donde hay gestión de negocios ajenos surge la consiguiente obligación de ofrecer el resultado contable, y entendiendo el vocablo «gestión» en el amplio sentido de manejo, administración, disposición o posesión, pues comprende los actos jurídicos, los puramente económicos y aun los simplemente materiales, según se desprende de los concretos supuestos que la jurisprudencia ha contemplado".

${ }^{16}$ Precisamente uno de los principales argumentos que avala esta tesis es que el propio Código Civil prevé en su artículo 1894 CC como supuesto de gestión de negocios ajenos la gestión alimenticia o prestación de alimentos por un particular no obligado a prestarlos y esta actuación no puede describirse exclusivamente como la realización de un acto jurídico. Ver SANCHEZ JoRDÁN, María Elena, La gestión de negocios...., ob.cit. p. 72.

${ }^{17}$ Roca SAstre, Ramón María/ PUIG Brutau, José; “La gestión de negocios ajenos sin mandato” en Estudios de Derecho Privado, Thomson Reuters Aranzadi, Navarra, 2009, p.529, Diez PicAzo, Luis; Comentario del Código Civil, Tomo II, Ministerio de Justicia, Madrid, 1991, p.1944, Vila RiBas, Carmen; “Gestión de negocios ajenos”, Enciclopedia Jurídica Básica, T.II, Civitas, Madrid, 1995, p. 3244-3246.

${ }^{18}$ Ver sentencia del TS de fecha 2 de abril de 1929 en Tribunal Supremo-Sala de lo Civil, Sentencias y Autos dictados desde el 1 de enero al 30 de junio de 1929 y publicados en la Gaceta de Madrid, n 315-316, 1929, Tomo I, Suc. De Rivadeneira, Madrid, 1931, p.600, en ésta se constata que el cuidado del incapaz psíquico al morir el hermano es asumido por los sobrinos que vendieron por cuenta de aquél, pero en nombre propio fincas que le pertenecían.
} 
conforme a lo establecido en el artículo 1.888 del Código Civil” ${ }^{19}$. Finalmente, también la STS 16.10.1978 (RJ 1978\3076) señala como objeto de la gestión de negocios ajenos tanto los actos jurídicos puramente económicos como los simplemente materiales.

Este debate queda orillado en el CCC, ya que en la definición de la institución propuesta por el art. 622-40 la sustitución del término negocio por el de "asunto ajeno" permite identificar un concepto amplio de gestión que incluye cualquier actividad actuada en interés ajeno, y que se refiere a tanto a la "gestión jurídica o material” y así el citado precepto indica que el gestor está obligado a continuar "la gestión jurídica o material hasta finalizarla o a requerir al titular, al representante o al administrador que lo sustituya en la gestión comenzada”, expresiones ambas más acordes con la interpretación propuesta. En conclusión, la gestión puede consistir tanto en la realización de un acto jurídico (el gestor paga una deuda o encarga una reparación) como en un acto material (el propio gestor alimenta, limpia, repara).

\subsection{La gestión de "un asunto ajeno, con motivo razonable y sin un encargo ni una obligación previa"}

\section{a. La gestión espontánea de un asunto ajeno}

La gestión ha de ser espontánea, es decir ser un acto unilateral que no obedezca a encargo ni obligación. La intromisión espontánea deberá ser desinteresada con ánimo benéfico sin que ello signifique liberalidad o intención de no reclamar por parte del gestor ${ }^{20}$. Además, el gestor oficioso deberá actuar en interés de otro ¿Qué significa? La doctrina ha defendido que bastará que se actúe en interés de otro, aunque se den concurrencias con intereses propios ${ }^{21}$. Ahora bien, en este caso la jurisprudencia entiende que coexistiendo intereses de ambos sujetos para que haya gestión oficiosa deberá el gestor anteponer el interés ajeno al propio ${ }^{22}$.

En el CCC, el reconocimiento de que pueda existir un interés compartido entre el titular y el gestor o actuación en asuntos parcialmente ajenos resulta de los siguientes argumentos que el propio Código recoge:

En primer lugar, tal y como significa literalmente el Preámbulo de la Ley 3/2017 de 15 de febrero del Libro sexto del CCC la actuación parcialmente ajena del gestor se encuentra reconocida en otros preceptos del propio Código. Así, el CCC tipifica un supuesto de

\footnotetext{
19 Precisamente en este caso el demandado alega la naturaleza exclusivamente personal de los actos realizados para excluir la institución de gestión de negocios ajenos. Ver Considerando segundo de la Sentencia núm. 48 del TS de 2 de febrero de 1954, en Colección Legislativa de España, Jurisprudencia Civil, Tomo XXXIII, 1954, Graficas Iguina, Madrid, 1956, p. 411.

${ }^{20}$ Autores como Marco Molina, Juana denuncian que la práctica tiende a confundir o asociar el móvil desinteresado de la intervención con el propósito de no ser resarcido, en "La gestión oficiosa...” ob.cit. p. 1823

${ }^{21}$ Ver en este sentido SANCHEZ JORDÁN, María Elena, “De las obligaciones que se contraen sin convenio. Comentario al artículo 1888 CCE” en Cañizares Laso, A; De Pablo Contreras, P; Orduña Moreno, J; Valpuesta Fernandez; R (Dirs), Código Civil comentado, vol. IV, $2^{\circ}$ Edición, Cizur Menor, Navarra, 2016, p. 1310.

${ }^{22}$ Así la STS 13.2.1926 en Tribunal Supremo-Sala de lo Civil, Sentencias y Autos dictados desde el 1 de enero al 30 de junio de 1929 y publicados en la Gaceta de Madrid, 1929, Tomo I, Suc. De Rivadeneira, Madrid, 1931, p.600, SAP de Castellón 20.12.2004 (JUR 2005/82741)
} 
ajenidad en el seno de la actuación familiar, en concreto de la actuación de un cónyuge en nombre del otro, en el que no se puede hablar de un total desinterés en el negocio ajeno que se atiende dado que existe una previa relación familiar. El Código en el art. 231-4.4 CCC establece que a la gestión hecha por uno de los cónyuges en nombre del otro le son aplicables las reglas en materia de gestión de negocios (que puede ser en su caso bien mandato bien gestión de asuntos ajenos). También se reconoce que hay gestión de asuntos ajenos en los supuestos de alimentos por cuenta ajena de los arts. 237-7, 23711 y 237-12.2 CCC en los que se regula la prestación de alimentos por terceros cuando la persona obligada no los presta.

En segundo lugar, el art. 622-42.2 CCC de aplicación a la gestión de asuntos ajenos admite implícitamente la gestión de asuntos parcialmente ajenos al prever que, en este supuesto, se producirá una reducción de los derechos del gestor en proporción al beneficio que éste haya obtenido: "La existencia de interés del gestor en el asunto conlleva la reducción del importe de sus derechos en proporción al beneficio obtenido".

En tercer lugar, el art. 622-41.4 CCC regula la responsabilidad del gestor en este supuesto ya que le hace responsable, incluso en los supuestos de caso fortuito, si ha buscado su interés propio en detrimento del dueño del asunto: "El gestor no responde en los supuestos de caso fortuito, salvo que emprenda actuaciones arriesgadas o inusuales para el titular del asunto o que procure su propio interés en detrimento del titular del asunto".

En suma, el CCC admite de forma explícita una posible actuación parcialmente ajena del gestor en la que para que se dé el supuesto de gestión de asuntos ajenos bastará con que se actúe en nombre e interés de otro, aunque se den concurrencias también con intereses propios. Sin embargo, el código no resuelve la protección del tercero en este supuesto y tal y como ha denunciado parte de la doctrina hubiera sido oportuno prever una regla de responsabilidad solidaria de gestor y dueño frente a terceros cuando se trate de un asunto parcialmente ajeno ${ }^{23}$.

\section{b. $\quad$ La gestión con motivos razonables: el modelo del Derecho Civil catalán}

La pregunta que se plantea en torno a la figura que estudiamos es si toda actuación del particular sin encargo, realizada en interés del tercero, tiene cobertura jurídica en la gestión de asuntos ajenos. La cuestión es de qué forma pueden excluirse injerencias e intromisiones injustificadas o arbitrarias. En efecto, la institución de la gestión de asuntos ajenos presenta un desafío, la protección del titular del asunto, frente a la decisión discrecional del gestor que es quien, sin contar con el titular del asunto, pero sí con su propia apreciación valora la conveniencia o la utilidad de su intromisión ${ }^{24}$. La respuesta a esta cuestión es que a los efectos de evitar abusos se

\footnotetext{
${ }^{23}$ En este sentido se pronuncia De BARRón ARniches, Paloma; “Gestión de asuntos ajenos sin mandato...”, ob.cit. p. 375.

${ }^{24}$ Que en la actualidad no sólo se destaque la finalidad altruista de la figura, sino que se sume el criterio de la utilidad individual y mediatamente social para proteger al dominus de inmisiones arbitrarias se destaca en MARCo Molina, Juana; en “La gestión oficiosa de negocios ajenos...”, ob.cit. p. 1821, también en SANTOS BRIZ, Jaime; “artículo 1888” en Albaladejo, Manuel (Dir); Comentarios al Código Civil y Compilaciones Forales, T.XXIV; Edersa, Madrid, 1984, p. 47 y CuADRADO IgLESIAS; Manuel; “Configuración, fundamento y naturaleza de la gestión oficiosa de negocios ajenos” en CuADRADo IgLESIAS, Manuel/NúÑEz BoludA, María de los Desamparados (Dir), Estudios..., ob.cit., p.719.
} 
requiera que la injerencia en interés del otro, presupuesto de la existencia de gestión de asuntos ajenos, deba sustentarse en alguna justificación o utilidad ${ }^{25}$.

En todo caso, la calificación de la gestión como justificada tiene una consecuencia jurídica relevante pues atribuye la legitimación al gestor para reclamar el reembolso de los gastos realizados y la obligación del dueño de resarcirle, independientemente como veremos que se quiera aprovechar el resultado o que éste exista. En relación con el CCC, aunque el art. 622-40 CCC prevé como presupuesto de la gestión de negocios ajenos que la actuación deba realizarse con cualquier "motivo razonable" ("La persona que gestiona un asunto ajeno, con motivos razonables y sin un encargo ni obligación previa (...)”no define a qué se refiere este concepto.

Para identificar qué significación podemos atribuir al término "motivo razonable" utilizado en el CCC analizaremos en primer lugar qué criterios siguen los sistemas jurídicos para identificar que una gestión de negocios ajenos esté justificada. En una parte de los sistemas jurídicos ${ }^{26}$, la justificación de la gestión se mide por su utilidad y el momento de la gestión que se tiene en cuenta para decidir si es útil es el inicial. Por lo tanto, no se precisa el éxito de esta para que nazca la obligación indemnizatoria del dominus y si la gestión es considerada inicialmente útil el dueño asumirá el riesgo de la falta de éxito de las actividades del gestor.

Para calificar la gestión como útil pueden seguirse los siguientes dos modelos:

a) El modelo subjetivo que considera que, en caso de desconocerse la voluntad real del dueño, está justificada aquella gestión que coincide con el interés o con la voluntad presunta de éste. Este modelo es seguido en el Derecho alemán que distingue una gestión justificada de una no justificada según la interpretación del § $677 \mathrm{BGB}^{27}$. La primera, concordante con el interés y voluntad real o presunta del dominus atribuye al gestor una acción de reembolso. La segunda, en la que falta dicha coincidencia, el dominus sólo quedaría obligado a devolver lo obtenido como consecuencia de la gestión en virtud de las reglas que regulan el enriquecimiento injusto ${ }^{28}$.

\footnotetext{
${ }^{25}$ El concepto dual de utilidad inicial (utiliter coeptum) y utilidad final (utiliter gestum) fueron equiparados en la doctrina del Derecho Común, y se consideraron equivalentes, Así BADOSA Coll, Ferran, La Diligencia y la culpa del deudor en la obligación civil, Bolonia, 1987, p, 560, nota 8.

${ }^{26}$ Es así en el sistema italiano, en el artículo 2031 del Código Civil italiano de 1942 "Qualora la gestione sia stata utilmente iniziata, l'interessato deve adempiere le obbligazioni che il gestore ha assunte in nome di lui, deve tenere indenne il gestore di quelle assunte dal medesimo in nome proprio e rimborsargli tutte le spese necessarie o utili con gli interessi dal giorno in cui le spese stesse sono state fatte. Questa disposizione non si applica agli atti di gestione eseguiti contro il divieto dell'interessato, eccetto che tale divieto sia contrario alla legge, all'ordine pubblico o al buon costume”, y en el BGB alemán en función del § 677 del BGB transliterado ut infra.

${ }^{27}$ En este sentido prevé el § 677 BGB: “Quien gestiona un negocio para otro sin haberle sido encargado por éste o sin estar legitimado de otro modo por éste, debe gestionar el negocio como lo requiere el interés del titular del negocio tomando en consideración su voluntad real o presunta”

Ver traducción del BBG en LAMARCA MARQuÈs, Albert; Código Civil alemán, Marcial Pons, Madrid, 2013, p. 214 y comentario en Enneccerus, Ludwig/Lehmann, Heinrich; Tratado de Derecho civil. Derecho de obligaciones. T.II, vol $2^{\circ}$, trad. y anotado por BlAS PÉREZ GonZÁlez y Alguer, José, $3^{\text {a }}$ Edición, Bosch, Barcelona, 1966, p.623, y en MEIER, Johannes; Das subjektive System der Geschäftsführung ohne Auftrag: Die $\S \S$ 677-686 BGB im Lichte der zweigliedrigen subjektiven Theorie, Mohr Siebeck, Tübingen, 2019, p. 4 y ss.

${ }^{28}$ LOYAL, Florian; Die „entgeltliche“ Geschäftsführung ohne Auftrag: Grundlagen und Grenzen eines außervertraglichen Leistungsaustauschs, Mohr Siebeck; Tübingen, 2019, p.19 y ss.
} 
b) El modelo objetivo defiende que, en el caso de que el gestor ignore la voluntad real del dueño, la gestión se inicia útilmente cuando se emprende en aquellos supuestos en los que un buen padre de familia hubiera debido emprenderla, teniendo en cuenta las circunstancias económicas del dueño. Se utiliza una medida abstracta de diligencia media, con un nexo con los intereses del dueño lo que permite evitar intromisiones arbitrarias del gestor. Si éste actúa conforme este modelo, la gestión es útil. El dominus no podrá negarse a indemnizar al gestor alegando que él no hubiera querido llevar a cabo esa actuación ${ }^{29}$.

En el sistema catalán, el art. 622-40 CCC reconoce, que la justificación de la gestión es un requisito de existencia de la institución y sigue el criterio de que la gestión sea reconocida como realizada "con motivo razonable": "La persona que gestiona un asunto ajeno, con motivo razonable y sin un encargo ni una obligación previa". En consecuencia, toda gestión no realizada con "motivo razonable", no está justificada y no podrá ser calificada como gestión de asuntos ajenos ni activará las reglas de indemnización que actúan en esta institución. En este sentido la calificación de la actuación del gestor como actuación con “motivo razonable” actúa como mecanismo de control y de protección del dueño frente a posibles actuaciones discrecionales. Ahora bien ¿qué criterio debe ser aplicado para calificar la gestión como razonable? El CCC no regula de forma expresa qué criterio deberá seguirse para medir la "razonabilidad" de la actuación del gestor. Para resolver esta cuestión podemos acudir a los criterios formulados en el DCFR ya que el CCC parece haberse inspirado en sus normas al utilizar los conceptos allí propuestos en la ordenación de la gestión de asuntos ajenos.

Si bien el DCFR no nos facilita una definición de razonabilidad en la regulación de la gestión de asuntos ajenos, el Libro I que recoge las disposiciones generales ordena en su art. 1:104 que "la razonabilidad se verificará objetivamente teniendo en cuenta la naturaleza y el propósito de lo que se realiza, las circunstancias del caso y los usos y prácticas relevantes" ${ }^{30}$. Además una definición de razonabilidad en el ámbito del derecho contractual europeo la podemos encontrar en el art. 1:302 los Principios del Derecho contractual europeo (PECL) que prevé que la razonabilidad se puede atribuir a la actuación de la persona cuando ésta es de buena fe y se lleva a cabo en una determinada situación en el sentido que las partes considerarían razonable: "Under these Principles reasonableness is to be judged by what persons acting in good faith and in the same situation as the parties would consider to be reasonable. In particular, in assessing what is reasonable the nature and purpose of the contract, the circumstances of the case, and the usages and practices of the trades or professions involved should be taken into account".

Finalmente, a los efectos de interpretar cuándo la actuación del gestor se considera razonable el DCFR nos ofrece los siguientes criterios al prever el V-1-101 que el gestor no tiene un "motivo razonable para actuar" si: “a) tiene una oportunidad razonable de averiguar la voluntad del dueño del negocio, pero no lo hace o b) conoce o es razonable suponer que conoce que la gestión va en contra

\footnotetext{
${ }^{29}$ BADOSA Coll, Ferran, La Diligencia y la culpa del deudor ... ob.cit.p. 89, FERRARI, Sigfrido; Gestioni di affari...., ob.cit. p. 29

${ }^{30}$ Ver traducción del artículo I-1-104 en Jerez DeLGADo, Carmen (Coord); Principios, definiciones y reglas..., ob.cit., p. 307.
} 
de los intereses del dueño del negocio"31. Por lo tanto, según una interpretación a sensu contrario de esta norma, la actuación del gestor está justificada en los siguientes dos casos:

1) El gestor tiene un "motivo razonable" para actuar porque su actuación es acorde con la voluntad del dueño (real o presunta). El gestor puede realizar un negocio considerado objetivamente útil, pero estará justificado si es contrario a la voluntad del dueño, bien porque se conoce la voluntad y se contradice, bien porque el gestor nada hizo para conocerla.

Por ejemplo, la persona que corta el césped del jardín del vecino ausente sin saber si esa es su voluntad no es un gestor de negocios. En este caso, de la gestión no derivarán obligaciones para el dueño.

Pero ¿qué ocurre si la voluntad del dueño es irracional? Por ejemplo, se admitiría que estamos ante una actuación razonable, aunque sea contraria a la voluntad del dueño si actuamos en el caso de que el deseo de éste sea suicidarse como consecuencia del padecimiento de la crisis en un trastorno mental. Sin embargo, en otros supuestos, la razonabilidad de la actuación del gestor puede no ser tan clara, aunque con la gestión se busque el beneficio del dueño.

Por ejemplo, A conoce que B siempre ha querido comprar un sello muy caro. Estando B de vacaciones, A conoce que el sello se ha puesto a la venta y lo compra. A no realiza una gestión de asuntos ajenos ya que no intenta contactar con B para conocer su parecer y en el caso de no poder contactar, la acción admite ser postpuesta o no es razonable actuar sin el mandato de $\mathrm{B}^{32}$.

Es decir, según la regulación del DCFR el gestor tiene que desplegar toda la actividad posible para averiguar la voluntad del dueño (por ejemplo, localizarlo realizando una llamada) y en el caso de no poder contactar con éste, la gestión no estará justificada si puede ser postpuesta ${ }^{33}$. Pongamos un caso que la doctrina se plantea para analizar la figura de la gestión de asuntos ajenos ${ }^{34}$ :

María y Eduardo están intentando vender su casa de veraneo en el Pirineo, reciben varias ofertas de hasta 200.000 euros que rechazan por considerar que la casa vale más. Un día un empresario hotelero se interesa por la casa y ofrece a María 250.000 Euros. Eduardo está de viaje y María no quiere perder la oportunidad así que acepta la oferta. Los trámites para la venta los encarga María a Pedro el gestor que lleva los asuntos de su marido y éste formaliza contrato de compraventa privado con Samuel, el comprador y lo firma en nombre de los esposos. Samuel toma posesión de la casa y paga mensualidades y requiere a ambos cónyuges para el otorgamiento de la escritura pública. Eduardo que acaba de iniciar los trámites de separación matrimonial con su esposa María se niega a ello y argumenta que no consistió la compraventa ni autorizó a su gestor.

\footnotetext{
${ }^{31}$ Ver traducción del artículo V-1-101 en Jerez Delgado, Carmen (Coord); Principios, definiciones y reglas.., ob.cit, p. 307.

${ }^{32}$ Ejemplo propuesto por Von BAR, Christian en su comentario al art 1.101.2 DCFR; Benevolent Intervenion in Anothers Affairs, Sellier European Law Publishers, Munich, 2006, p. 119.

${ }^{33}$ Así en comentario al art 1.101.2 DCFR en Von BAR, Christian; Benevolent Intervenion ...., ob.cit.p. 119.

${ }^{34}$ Caso propuesto por De BARRón ARniches, Paloma en su trabajo "Gestión de negocios ajenos sin mandato....”, ob.cit. p. 373.
} 
En este supuesto de actuación de un cónyuge en nombre del otro, como ya se ha analizado ut supra, el art. 231-4.4 CCC nos remite a los arts. 622-40 y ss que regulan la gestión de asuntos ajenos. Por lo tanto, deberemos analizar si la gestión realizada puede ser calificada como gestión de asuntos ajenos ¿Se puede calificar la actuación de María como actuación con "motivo razonable" de conformidad con el art. 622-40 CCC? ¿Tiene María un motivo razonable para realizar una injerencia en la esfera jurídica de su cónyuge?

Pues bien, siguiendo el criterio propuesto en el DCFR deberá valorarse si la actuación de María ha sido con "motivo razonable". Es decir, si María desplegó toda la actividad posible para contactar con su marido y conocer su parecer según las actuales vías de comunicación posibles: teléfono móvil, correo electrónico...etc. Y en caso de que se pruebe que hubo intención de comunicar con el dueño ${ }^{35}$, la gestión se realiza con "motivo razonable" si se prueba que la gestión no puede ser postpuesta porque en el caso de serlo se produciría un daño para el dueño.

Lo que nos lleva a fundamentar la razonabilidad de la actuación del gestor en dos presupuestos: $1^{\circ}$ ) En la intención del gestor de conocer la voluntad del dueño, y entonces hay que concluir que hay poca probabilidad de que una gestión se considere gestión de asuntos ajenos si no ha existido una intención de comunicar con el dueño par parte del gestor y; $2^{\circ}$ ) De forma subsidiaria y en caso de que la comunicación no haya sido posible la gestión será razonable ni no puede ser postpuesta, lo que conduce a su valoración como urgente o que en caso de no realizarse se produciría un perjuicio al dueño. En este caso se ha de significar que, si la actividad del gestor es de contenido personal, en atención al bien jurídico que se protege, la vida, la gestión podría ser considerada en la mayoría de los casos como necesaria y urgente. Son urgentes y necesarios aquellos actos materiales que contribuyen a cuidar del tercero (facilitar alimentos, vestirlo...etc.). Pero, cuando la actividad del gestor tenga un contenido patrimonial, la urgencia se producirá si en caso de postponer la gestión se causa un perjuicio o daño al dueño ${ }^{36}$.

2) El gestor tiene un "motivo razonable" para actuar porque la gestión se ha realizado según los intereses del dueño, que o bien se conocen o bien es "razonable suponer que se conocen". A sensu contrario, no podrá considerarse justificado aquel negocio (adquirir un bien a precio inmejorable) que es razonable suponer que va en contra de los intereses del dueño (porque éste no puede pagar por su situación o porque no lo necesita). Por lo tanto, la gestión no se realiza con motivos razonables si el gestor "conoce o es razonable suponer que conoce que la gestión va en contra de los intereses del dueño del negocio". Si volvemos al anterior ejemplo, podría cuestionarse si la gestión realizada por María pudo ser también no razonable, porque María pudo conocer, dada la situación de crisis que la pareja podía estar atravesando, que la gestión (venta de la casa) ya no interesaba en ese momento a su marido.

\footnotetext{
${ }^{35}$ Así deberá valorarse el tiempo y el coste de contactar con el principal ya que en algunos casos la actuación si es urgente no admitirá ser postpuesta y tampoco se podrá perder el tiempo en hacer la gestión de contactar. Ver Von BAR, Christian/Clive, Eric/Schulte-NölKe, Hans; Principles, Definitions, Model Rules of European Private Law Draft Common Frame of Reference (DCFR), V, 1:101, Comments, Interim on line edition, 2008, p. 1223.

${ }^{36}$ Tesis defendida por SÁnCHEZ JoRDÁn, Ma Elena, La gestión de negocios..., ob.cit. p.293.
} 
En suma, la razonabilidad de la actuación del gestor quedará sometida a la prueba de si éste tuvo oportunidad de descubrir la voluntad o interés de dueño y en caso de no ser así a la valoración de si la actuación admitía ser realizada más adelante.

\section{c. La actuación del gestor en interés general a modo de "motivo razonable" implícito}

En un supuesto excepcional la actuación del gestor será justificada porque lleva implícita la "razonabilidad", incluso en el caso que se dé la expresa voluntad contraria del dueño: cuando la no intervención del gestor suponga un incumplimiento de una obligación de interés general. Así se ha manifestado la doctrina española ${ }^{37} \mathrm{y}$ ha sido previsto en el DCFR cuyo artículo V-1:102 dice: "Cuando un gestor actúe para cumplir un deber de otra persona, cuyo cumplimiento es debido, urgente y necesario por ser un asunto de interés público prioritario y actúe con la intención principal de favorecer a la persona beneficiaria del cumplimiento del deber, la persona en cuyo favor se cumple el deber por parte del gestor será el dueño del negocio en el sentido del presente Libro" ${ }^{38}$.

Este precepto se refiere a la intervención del gestor para ejecutar un deber del dueño cuyo cumplimiento puede considerarse de "interés general" lo que implica dos consecuencias importantes:

$1^{\circ}$ ) Que el deber que permite calificar la gestión de justificada no se circunscribe exclusivamente a los deberes de Derecho Público sino también a los de Derecho Privado $^{39} ; \mathrm{y}$

$2^{\circ}$ ) Que deberá probarse la existencia de un interés que sea general para legitimar aquella gestión realizada incluso pese a la oposición del dueño. No basta con que el carácter del deber sea de Derecho público (por ejemplo, una deuda tributaria) para amparar la intromisión en el asunto ajeno en contra de la voluntad del dueño ${ }^{40}$. En todo caso, concurrirá un interés general si el incumplimiento de la gestión del asunto ajeno pone en riesgo o compromete la vida, la integridad física o la propiedad de terceros.

\footnotetext{
${ }^{37}$ Ver SÁNCheZ JoRdÁn; María Elena; La gestión....., ob.cit. p. 290, LACRUZ BeRDejo, Manuel; La gestión de negocios ..., ob.cit. p. 261 y 262 que pone de ejemplo la salvación de un suicida.

${ }^{38}$ Artículo V-1:102: “Where an intervener acts to perform another person's duty, the performance of which is due and urgently required as a matter ofoverriding public interest, and the intervener acts with the predominant intention of benefiting the recipient of the performance, the person whose duty the intervener acts to perform is a principal to whom this Book applies", la traducción del texto en JEREZ DELGADo, Carmen; Principios, definiciones..., ob.cit. p.307.

${ }^{39}$ Este precepto sigue el modelo establecido en el §679 BGB alemán que contempla como gestión ajena justificada aquella que cumple un interés general e incluye en éste tanto deberes de Derecho público como de Derecho privado “\$ 679 BGB: „Ein der Geschäftsführung entgegenstehender Wille des Geschäftsherrn kommt nicht in Betracht, wenn ohne die Geschäftsführung eine Pflicht des Geschäftsherrn, deren Erfüllung im öffentlichen Interesse liegt, oder eine gesetzliche Unterhaltspflicht des Geschäftsherrn nicht rechtzeitig erfüllt werden würde. "ver comentario en ReUTER, Dieter; I Von Staudinger, Kommentar zum Bürgerlichen Gesetzbuch mit Einführungsgesetz und Nebengesetzen, 2. Buch, Recht der Schuldverhältnisse §§ 657-704, 14., Sellier-de Gruyter, Berlin, 2006, p. 695.

${ }^{40}$ La jurisprudencia ha declarado que el pago de una deuda tributaria contra la voluntad de su titular no puede ser sin más considerada como gestión de negocios ajenos. En este sentido sentencia del TS de 18 de mayo de 1946 transliterada en MARCo MolinA, Juana; La gestión oficiosa...., ob.cit. p.1822, nota 16.
} 
Así por ejemplo la sentencia de la Audiencia Provincial de Barcelona de 5.12.2015 (JUR $2015 \backslash 62109)$ admite como gestión de asuntos ajenos la actuación del gestor pese a la oposición del dueño ${ }^{41}$. En este caso se trataba de un edificio que tiene acceso a través de la escalera y patio de otro edificio. El propietario del primer edificio realizó y pagó las obras en la escalera y patio del edificio contiguo que se encontraba en muy mal estado. Se reclama al propietario del edificio contiguo la mitad del coste de las obras al amparo del art 1893 CC. Dada la situación de peligrosidad para los habitantes de los inmuebles la sentencia admite la existencia de gestión de asuntos ajenos pese a la oposición del dueño del edificio contiguo a la realización de las obras. Aunque la sentencia no lo reconoce explícitamente se está ante el supuesto excepcional que justifica la injerencia del gestor pues éste ejecuta un deber del dueño cuyo cumplimiento se considera de interés general. En este caso, la actuación se ajustaría a una actuación con "motivo razonable".

Por otra parte, hay deberes privados como la obligación de alimentos entre parientes cuyo cumplimiento por terceros aún contra la voluntad del obligado queda legalmente legitimado. Sin duda en esta gestión subyace un interés social que la justifica implícitamente. Así el artículo 1894.1 CC dice "Cuando sin conocimiento del obligado a prestar alimentos, los diese un extraño, éste tendrá derecho a reclamarlos de aquél, a no constar que los dio por oficio de piedad y sin ánimo de reclamarlos”, mientras, el art. 237.11 CCC ordena que "La entidad pública o privada o cualquier otra persona que preste alimentos, si la persona obligada no lo hace, puede repetir contra esta última o sus herederos las pensiones correspondientes al año en curso y al año anterior, con los intereses legales, y subrogarse de pleno derecho, hasta el importe indicado, en los derechos que el alimentado tiene contra la persona obligada a prestarlos, salvo que conste que se dieron desinteresadamente y sin ánimo de reclamarlos (art. 237.11 CCC)”42.

La reclamación de alimentos, siempre que el obligado realice la gestión sin "oficio de piedad” y con ánimo de reclamarlos, se articula en el CC mediante una acción ordinaria de reembolso o de repetición ${ }^{43}$; mientras el CCC prevé medios privilegiados de reembolso del tercero que asiste al necesitado. Así, el tercero pagador podrá subrogarse en el crédito pagado con la ventaja de preservar la antigüedad y, en su caso, los derechos de garantía accesorios. Finalmente, con relación a la "falta de conocimiento del obligado a prestar alimentos" requisito previsto en la acción de reembolso del CC, la doctrina mayoritaria considera que en este caso el Código se refiere a que, a pesar del conocimiento o prohibición del dueño éste quede obligado si el gestor cumple con un deber de alimentos que le incumben. Esta interpretación que permite la compatibilidad entre una actuación contraria a la voluntad del dueño con el nacimiento de la acción a favor del agente se

\footnotetext{
${ }^{41}$ Ver sentencia de la Audiencia Provincial de Barcelona de 5 de diciembre de 2015 (JUR $\backslash 2015 \backslash 62109$ ).

${ }^{42}$ El artículo 237-11 CCCat no ha sufrido cambio alguno de su antecesor, el art. 269 CF, ver comentario en DurAny Pich, Salvador; “Art. 237-11” en EgEA I FERnÁNDEZ, Joan/FERRER I RiBA; Josep; Comentari al llibre segon del Codi Civil de Catalunya, Atelier, Barcelona, 2014, p.1022-1025.

${ }^{43}$ La doctrina exige que los requisitos se den cumulativamente para excluir la reclamación, por lo tanto, aunque el extraño facilite los alimentos por "oficio de piedad” los podrá reclamar, pues se requiere que cumulativamente no haya ánimo de reclamarlos. En este sentido LASARTE, Carlos; “Art. 1894” en Comentario del Código Civil, T.II, Ministerio de Justicia, Madrid, 1991, p. 1953.
} 
fundamenta en el interés social subyacente en la gestión alimenticia ${ }^{44}$. En el CCC, esta cuestión no se plantea pues el hecho de que no se haga referencia al desconocimiento de la gestión por parte del obligado a prestar alimentos, legitima cualquier supuesto de gestión alimenticia, incluso la gestión efectuada sin la voluntad o ante el desinterés del obligado ${ }^{45}$.

\section{d. La actuación del gestor no oficiosa: un supuesto de enriquecimiento injustificado}

En el caso de que la actuación del gestor sea realizada sin un “motivo razonable”, la actuación no podrá ser calificada como gestión oficiosa y por tanto no nacerán a cargo del dueño y del gestor las obligaciones previstas en el CCC, que principalmente son para el gestor, la de continuar la gestión hasta finalizarla o bien requerir al titular para que le sustituya y en el dueño, el deber de resarcir al gestor aunque no quiera aprovechar el resultado de la gestión o aunque no se haya obtenido ningún resultado (art. 622-42 CCC).

Puede darse el caso de que no se pueda calificar la gestión de oficiosa bien porque la actuación se realiza sin motivo razonable, pero también si ésta no cumple con los demás requisitos exigidos en el 622-40 CCC, es decir gestión de "un asunto ajeno, con motivo razonable y sin un encargo ni una obligación previa”. Entonces, el art. 622-42.4 CCC, en el mismo sentido que en Derecho civil alemán, y, por lo tanto, siguiendo el modelo subjetivo, prevé que el gestor que actuó también pueda ser resarcido, pero según las reglas del enriquecimiento injustificado ${ }^{46}$ : "El gestor si su pretensión no se ajusta a los requisitos de la gestión de asuntos ajenos, puede recurrir a las reglas de enriquecimiento injustificado".

Una parte de la doctrina denuncia que la gestión de asuntos ajenos debe quedar excluida del enriquecimiento injustificado, ya que en aquélla predominaría el sacrificio o empobrecimiento del gestor y no el enriquecimiento del titular del negocio que puede incluso faltar pues la

\footnotetext{
${ }^{44}$ En este sentido se pronuncia LACRUz BERDEJO, José Luis; “La gestión de negocios....”, ob.cit. p.252 que reconoce la antinomia existente entre el 1894 CC y el art 1158 CC y que entiende que en atención al interés social subyacente debe resolverse a favor del segundo: "puede hacer el pago cualquier persona, tenga o no interés en el cumplimiento de la obligación, ya lo conozca y lo apruebe, o ya lo ignore el deudor. El que pagare por cuenta de otro podrá reclamar del deudor lo que hubiese pagado, a no haberlo hecho contra su expresa voluntad. En este caso sólo podrá repetir del deudor aquello en que le hubiera sido útil el pago", SÁNCHEZ JORDÁN; $\mathrm{M}^{\mathrm{a}}$ Elena, "Art- 1894" en Cañizares Laso, Ana/De Pablo Contreras, Pedro/ORduÑa Moreno, Javier/ValPuesta Fernández, Rosario (Dir); Código Civil Comentado, Vol. IV, $2^{\text {a }}$ Edición, Thomson Reuters Civitas, Navarra, 2016, p.1333.

En contra autores como LASARTE Carlos; "Art 1894" en Comentario del..., ob.cit. p.1954, que defiende desvincular la interpretación del art. $1894 \mathrm{CC}$ de los preceptos reguladores del pago por tercero e interpreta que el dato relevante es la intervención del solvens desconocedor de la existencia de un obligado a prestar alimentos. De forma que, existiendo dicho desconocimiento, el solvens es considerado especial gestor de negocios ajenos y tiene derecho a reclamar las cantidades destinadas a los alimentos, por el contrario, si conoce la existencia del obligado o alimentante, entran en juego las reglas propias del pago de tercero y entonces sí tendrá relevancia la actitud del deudor frente a dicho pago del 1158 y 1159 CC.

${ }^{45}$ Así en DuRANy Pich, Salvador; “Art. 237-11”, ob.cit., p. 1022-1025.

${ }^{46} \mathrm{El}$ enriquecimiento injusto es fuente obligacional autónoma ya que no se trata de reparar un daño sino de restablecer el equilibrio entre dos patrimonios. En consecuencia, no se debe emplear el termino de indemnización sino el de restitución. En este sentido vid MARCo MoLina, Juana "L'enriquiment injustificat. Proposta de regulació per al futur Llibre sisè del Codi Civil de Catalunya”, Revista Catalana de Dret Privat, vol 15-1, 2015, p. 39.
} 
reclamación del gestor nace, aunque la gestión diligente haya sido inútil ${ }^{47}$. Coincidimos plenamente en la delimitación entre ambas figuras, gestión de asuntos ajenos y enriquecimiento injustificado criterio que creemos sigue el CCC ya que sólo hay remisión a las reglas del resarcimiento injustificado en el caso de que la actuación del gestor no pueda ser calificada como oficiosa o gestión de asuntos ajenos porque no cumpla los requisitos de su existencia (art. 62242. 4 CCC).

Es entonces y sólo entonces cuando el gestor puede acudir a las reglas del enriquecimiento injustificado que actuarán a modo de corrección de un enriquecimiento (sea positivo o negativo) provocado por un desplazamiento que, siendo lícito o ajustado a derecho, no puede ser retenido por su destinatario por no estar justificado. Por lo tanto, la falta de causa o justificación no se predica del desplazamiento efectuado sino de la legitimación o facultad del destinatario de la atribución para mantener en su patrimonio el valor recibido ${ }^{48}$. Lo que se procura es, no tanto revertir el desplazamiento que se considera lícito sino corregirlo haciendo nacer una nueva obligación (de sentido inverso a la atribución efectuada) entre los sujetos de la relación. Se trata de una obligación personal de restitución de un valor que tiene como deudor al dueño de la gestión no oficiosa (destinatario de la atribución) y como acreedor al gestor que la realizó (titular del patrimonio del que se desplaza el activo transferido). Por lo tanto, en el caso de que la gestión no pueda ser calificada de gestión oficiosa pero el dueño haya sido beneficiado por la gestión, estará obligado a restituir lo obtenido y si no es posible la restitución específica o in natura, el pago de su valor o equivalente económico.

\section{Consecuencias de la calificación de la actuación como gestión de asunto ajeno: breve análisis.}

Cuando la actuación del gestor cumpla con los requisitos del art. 622-40 CCC, es decir, sea una gestión de "un asunto ajeno, con motivo razonable y sin un encargo ni una obligación previa", y no pueda ser reconducida a las reglas del mandato por no existir ratificación de la gestión, serán de aplicación las reglas previstas en los arts. 622-40 CC a 622-42 CCC que establecen los deberes del gestor y las obligaciones del dueño del asunto gestionado y que analizaremos brevemente.

Con relación a la actuación del gestor el art. 622-41 CCC le impone los mismos criterios de diligencia que el art. 622-27.2 CCC exige al mandatario. En concreto, como criterio general, el gestor debe actuar con la diligencia propia de una persona razonable, de acuerdo con la naturaleza del asunto. En el caso de que el gestor actúe en ejercicio de su oficio o actividad profesional, debe aplicar la correspondiente diligencia profesional. En este supuesto de actuación profesional del gestor, la doctrina se plantea si está justificada su remuneración ya que la normativa catalana, fuera del caso en el que estemos ante un mandato porque el dueño

\footnotetext{
${ }^{47}$ Ver en este sentido la crítica en DE BARRón ARniches, Paloma en su trabajo “Gestión de negocios ajenos sin mandato.", ob.cit. p. 371 quien en su crítica a la regulación del CCC sigue el razonamiento de BADOSA CoLL, Ferran; "El enriquecimiento injustificado. La formación de su concepto” en BosCH CAPDEVILA, Esteve (Dir); Nuevas perspectivas del Derecho contractual europeo; Bosch; Barcelona, 2012, p. 111 y 112.

${ }^{48}$ Ver Marco Molina, Juana; “L’enriquiment injustificat. Proposta de regulació per al futur Llibre sisè....”, ob,cit, p. 22.
} 
ratifique la gestión, no contempla el pago de honorarios al gestor, aunque sea profesional ${ }^{49}$. Los autores que se posicionan a favor de admitir esta posibilidad se fundamentan en los siguientes argumentos: $1^{\circ}$ ) que el pago de honorarios incentivaría al profesional a actuar cuando considere que su actuación está justificada, aunque no tenga un mandato expreso $0^{50} 2^{\circ}$ ) que es incongruente exigir al gestor profesional una mayor diligencia si no se admite en contrapartida que su actuación pueda ser remunerada ${ }^{51} \mathrm{y} ; 3^{\circ}$ ) que el profesional pueda cobrar si es llamado por el gestor pero no si actúa por propia iniciativa sobre el asunto ajeno supone una falta de coherencia. En nuestra opinión ${ }^{52}$, fundamentar la retribución del gestor oficioso en estos argumentos, aunque legítimos, implica alejarnos de la naturaleza jurídica de la institución que estudiamos. Recordemos brevemente que con la gestión oficiosa se contempla como legítima, aunque excepcional, la intervención o actuación por parte de un sujeto (el gestor) en la esfera jurídica ajena, sin previa autorización de su titular. Creemos que el legislador catalán acorde con la naturaleza de la figura inadmite en este supuesto el pago de honorarios al gestor: $1^{\circ}$ ) Porque estamos ante un acto jurídico unilateral no negocial del que no nace ningún tipo de obligación recíproca ni sinalagmática y por tanto tampoco obligación de retribuir honorarios, y $2^{\circ}$ ) porque la intervención espontánea del gestor profesional será casi residual ya que para ser calificada de gestión oficiosa, deberá cumplir los requisitos del art. 622-40.1 CCC lo que supone que, el gestor profesional, deberá probar que en caso de no poder contactar con el titular la gestión no admitía aplazamiento. Lo que, como ya se ha estudiado ut supra, sucederá en muy pocos supuestos.

Como principal y fundamental obligación, el gestor que inicia su gestión tiene la obligación de continuar con ella hasta finalizarla o bien a requerir al titular, a su representante o al administrador que lo sustituya en la gestión comenzada (art. 622-40.1 CCC). Este deber del gestor se fundamenta en el deber de actuar con diligencia, dado que dejar una gestión a medias supone una infracción de tal deber. Por otra parte, según el art. 622-40. 1 CCC el gestor puede "requerir al titular, al representante o al administrador que lo sustituya en la gestión comenzada". La interpretación de la doctrina es que, si el requerimiento del gestor no es atendido, podrá liberarse de su obligación y abandonar la gestión ${ }^{53}$.

Con relación a la responsabilidad del gestor, éste es responsable de los daños que, por infracción de la diligencia exigible, se causen al titular del asunto, pero también responderá por los daños

\footnotetext{
49 A diferencia del contrato de mandato en el que el artículo 622-24.1 CCC si contempla el pago de honorarios: "1. El mandato se presume gratuito, salvo que se haya pactado otra cosa o que el mandatario ejerza profesionalmente la actividad encomendada”.

50 Del Pozo Carrascosa, Pedro/Vaquer Aloy, Antoni/ Bosch Capdevila, Antoni; Derecho Civil de Cataluña. Derecho de obligaciones y contratos, Marcial Pons, Madrid-Barcelona, 2018, p. 788.

${ }^{51}$ Vid en De BARrón ARniches, Paloma; Gestión de negocios ajenos sin mandato....”, ob.cit. p. 380 aunque la autora sólo reformula los argumentos a favor de la remuneración del gestor oficioso profesional recogidos en la Exposición de Motivos (p. 238) de la Propuesta del Código Civil de la Asociación de Profesores de Derecho Civil: "En favor de esta opción cabe argumentar la ausencia de ánimo de liberalidad, la más rigurosa responsabilidad exigible a un profesional y la incongruencia que supone que el profesional pueda cobrar si es llamado por el gestor pero no si actúa por propia iniciativa sobre el asunto ajeno". La obra se puede consultar en http://www.derechocivil.net/publicaciones/propuesta-codigo-civil (consultada en fecha 6 de agosto de 2020).

${ }^{52}$ Exposición de Motivos (p. 238) de la Propuesta del Código Civil de la Asociación de Profesores de Derecho Civil: La obra se puede consultar en http://www.derechocivil.net/publicaciones/propuesta-codigo-civil (consultada en fecha 6 de agosto de 2020).

${ }^{53}$ Del Pozo Carrascosa, Pedro/Vaquer Aloy, Antoni/ Bosch Capdevila, Antoni; Derecho Civil de Cataluña..., ob.cit. p.786.
} 
ocasionados por una interrupción injustificada de la gestión pues su obligación es continuarla hasta su finalización. Además, la responsabilidad del gestor puede atenuarse o eliminarse en caso de culpa del titular del asunto o de intervención de un tercero (art. 622-41.3 CCC). Aquí el CCC se refiere a cualquier tercero distinto del gestor que se encargue del asunto (por ejemplo, el mandatario que el titular ha designado para gestionar el mismo asunto sin que el gestor haya tenido noticias de ello).

Respecto a la responsabilidad, algunos autores se cuestionan en qué intensidad deber ser exigida dado que estamos ante la actuación de alguien que de forma voluntaria se ocupa de los intereses ajenos y como solución proponen una posible aplicación de la facultad de moderación implícita en el principio de equidad que pueden ejercer los tribunales de conformidad con el art.3.2.CC. Siguiendo esta línea argumental, el art. 622-41 CCC prevé que el gestor no responda de los supuestos de caso fortuito salvo que "emprenda actuaciones arriesgadas o inusuales para el titular del asunto o que procure su propio interés en detrimento del titular del asunto. En ningún caso responde en los supuestos de fuerza mayor". Ahora bien, el CCC hace responsable al gestor de los actos de su delegado o sustituto (art. 622-41.5 CCC).

Con relación a la gestión el CCC prevé el deber del gestor de rendir cuentas de su actividad y facilitar información al titular del asunto mientras dure la gestión (si es posible) y una vez finalizada ${ }^{54}$. De conformidad con el art.622-41. 6 CCC: "El gestor, una vez finalizada la gestión o, si es posible, durante la ejecución de esta, debe informar al titular del asunto de la gestión efectuada o, si procede, del curso de la que está efectuando, rendirle cuentas y, si procede, poner a su disposición lo obtenido en el curso de la gestión.”.

Con relación a la obligación de resarcimiento e indemnización del dueño, el art. 622-42.1 CCC, prevé que bastará la existencia de una ventaja objetiva, de un estado objetivo de producción de esta para que nazca la obligación legal del dueño de resarcir al gestor, independientemente de que se haya dado efectivamente un resultado o de que el dueño aproveche la ventaja o se niegue a recibirla. Así resulta de la redacción del precepto: "el titular del asunto, aunque no quiera aprovechar el resultado de la gestión o, aunque no se haya obtenido ningún resultado, está obligado a: a) resarcir gastos útiles y necesarios efectuados en su interés. Las cantidades anticipadas por el gestor devengan interés legal desde el día del pago. (..) b) indemnizar al gestor por los daños y perjuicios y c) liberar al gestor de las obligaciones contraídas en su interés)."

En correlación con esta obligación de resarcimiento, el contenido informativo de la rendición de cuentas del gestor no sólo se circunscribirá a la gestión y entrega de lo obtenido, sino que incluirá el detalle de aquellos gastos que deban ser reembolsados por el titular de la gestión (gastos necesarios y útiles efectuados en su interés ${ }^{55}$ ), el interés legal por las cantidades que el gestor haya tenido que adelantar calculado desde el día del pago y la cuantía en la que valora el gestor la indemnización de los daños y perjuicios producidos con ocasión de la gestión oficiosa (tanto daño emergente como lucro cesante por ejemplo perjuicios ocasionados por posponer sus asuntos). Además, también deberá informar al titular de aquellas obligaciones contraídas en su interés ya que el titular del asunto debe "liberar al gestor de las obligaciones contraídas en su

\footnotetext{
${ }^{54}$ La jurisprudencia ya se había pronunciado sobre el deber del gestor de rendir cuentas de su actividad, Vid SSTS de 16.10.1978 (RJ 1978/3076) y de 19.12.1983 (RJ 1983/6967).

${ }^{55}$ De conformidad con el art. 622-42.3 CCC: "La utilidad o la necesidad de los gastos efectuados y la de las obligaciones contraídas deben valorarse atendiendo al momento en que se efectuaron o contrajeron".
} 
interés". Es decir, que es el titular quien debe asumir la carga económica de la extinción de una obligación contraída en su interés de la que el gestor es formalmente deudor, bien pagando la deuda, bien entregando su importe al gestor.

\section{El conocimiento de la gestión oficiosa por el dueño}

Fuera de los casos en los que el gestor actúe porque el dueño esté ausente, pueden darse casos en los que el particular, conozca la actuación del gestor. Tanto el CCC como el CC parecen admitir esta posibilidad. El CCC la admite implícitamente al reconocer el deber del gestor de mantener informado, si es posible, al titular del asunto durante la ejecución de la gestión: "El gestor, una vez finalizada la gestión o, si es posible, durante la ejecución de esta, debe informar al titular del asunto de la gestión efectuada" (art. 622-41.6 CCC). Por su parte, el hecho de que, en el art. 1888 CC, se omitiera el requisito de que el dueño no conociera la gestión oficiosa que sí exigía el Proyecto de 1851, pone de manifiesto que el CC no se opone a un posible conocimiento de la gestión.

En estos casos de conocimiento del titular, dos pueden ser los supuestos que se planteen:

\section{La inactividad o silencio del titular pese al conocimiento de la gestión: "el silencio expresivo"}

¿Qué valor jurídico se atribuye al conocimiento de la gestión por el dueño en caso de inactividad? En estos supuestos se cuestiona si el silencio del dueño podría ser interpretado como un consentimiento tácito a un contrato bien de mandato o bien de arrendamiento de servicios ${ }^{56}$. La atribución de valor jurídico al silencio no puede recibir una respuesta unívoca para todos los casos. Según el criterio general, la presencia y conocimiento por parte del interesado de la intervención del gestor, siempre que no manifieste su oposición, no atribuye al silencio o inactividad la calificación de manifestación de voluntad. Será en palabras de algún autor una manifestación de “inercia" frente a la actuación del gestor ${ }^{57}$. Se presenta aquí una difícil distinción entre mandato tácito y gestión oficiosa de negocios ajenos. En efecto, nos preguntamos cuándo el conocimiento de la gestión por el dueño pueda ser considerado consentimiento tácito. En nuestra opinión, la naturaleza de la gestión de negocios ajenos se sitúa en una efectiva actuación del gestor, que constituye un acto jurídico no negocial en sentido estricto. Ahora bien, la inactividad del dueño, en caso de conocimiento de la gestión, puede ser interpretada como manifestación de voluntad en aquellos supuestos

\footnotetext{
${ }^{56}$ Ésta era la postura seguida por el Proyecto de 1851 cuyo artículo 1892 exigía que el dueño no conociera la gestión oficiosa, finalmente la referencia al conocimiento queda excluida en el CC. GARCIA GoYENA, Florencio, Concordancias, motivos y comentarios del Código Civil Español, Editorial Cometa, Zaragoza, 1974, p.962, en su comentario al artículo 1892 del proyecto de 1851 entiende que la exigencia de no conocimiento de la gestión por parte del dueño determina que en caso de conocimiento, nos encontremos ante un mandato tácito " habemos admitido el mandato tácito y lo reconocemos siempre que el propietario tiene noticia de la agencia o administración”.

${ }^{57}$ En este sentido LACRUZ BERDEJo, José Luis; “La gestión de negocios sin mandato”, en Revista Critica de Derecho Inmobiliario, núm. 507, marzo-abril, 1975, p.252.
} 
en los que la buena fe imponga un deber positivo de expresar una oposición o repulsa ${ }^{58}$. El silencio es aquí contemplado como un hecho que se produce en un contexto relacional, una especie de hecho concluyente que requiere de interpretación. De esta actividad interpretativa pueden resultar dos conclusiones:

a) manifestación tácita de voluntad contractual: cuando la inactividad sea expresiva de una conformidad simultánea a la actuación del gestor y constituya el consentimiento tácito de un contrato bien de mandato (actos jurídicos) ${ }^{59}$, bien de arrendamiento de servicios (actos materiales). Sin embargo, entendemos que la prueba de una inequívoca voluntad de obligarse se presentará difícil en estos casos como así lo ha reconocido la jurisprudencia. Por ejemplo, la sentencia de la AP Madrid de 17 de diciembre de 2013 (JUR 2014\60689) analiza si la prolongada relación jurídica de administración patrimonial que existe entre un padre y una hija debe ser calificada de gestión de asuntos ajenos o de mandato tácito. Mientras la sentencia de instancia concluyó que quedaba probada la existencia de un mandato tácito, la sentencia de la Audiencia se posiciona a favor de la existencia de una gestión de negocios ajenos sin mandato pues considera que respecto a la existencia de un mandato tácito deberá exigirse que la voluntad tácita resulte de actos que impliquen necesariamente, de modo evidente e inequívoco la intención de obligarse, así como las facultades conferidas al mandatario ${ }^{60}$.

b) manifestación de voluntad ratificadora: cuando la inactividad coetánea a la gestión entrañe una aceptación de lo actuado por el gestor, entonces constituye un supuesto más de ratificación tácita (art. 1892 y 1727 CC,622-40CCC) ${ }^{61}$. Baste recordar aquí que cualquier actividad posterior del dueño que signifique aceptación (pago de gastos por ejemplo mediante realizar una transferencia, aceptar los beneficios que le reporta la gestión...etc.) ha de considerarse ratificación tácita y generará la

\footnotetext{
${ }^{58}$ El silencio es considerado como declaración contractual de voluntad cuando el modo corriente de proceder en la relación jurídica nacida entre dos personas implica el deber de hablar Recoge esta tesis intermedia, Diez PiCAzo, Luis; Fundamentos de Derecho Civil Patrimonial, T.I, Tecnos, Madrid, 1970, p. 105 y 106.

${ }^{59}$ A favor autores como PlAniol, Marcel/ RIPERT, Jorge; Tratado práctico de Derecho civil francés, , T.VII, Las obligaciones, $2^{\text {a }}$ Parte, Habana Cultural, 1945, p. 11 y ss., para quien el hecho de tener conocimiento de la gestión podrá considerarse como una ratificación respecto al pasado y como un mandato para lo futuro, En contra autores como MENÉNDEZ MATO, Juan Carlos, quien se cuestiona si en el caso de la gestión de negocios por tercero podría interpretarse que el hipotético mandatario fuese la persona que realizase la oferta tácita de mandato, pero defiende que en ningún caso se emite una declaración de voluntad negocial ni siquiera a través de un comportamiento concluyente o de un silencio cualificado, en "La oferta tácita del mandato" en Actualidad Civil, núm. 13, 29 marzo a 4 de abril de 1999, pp. 321-343, en concreto. p.340.

${ }^{60}$ Vid sentencia de AP Madrid de 17 de diciembre de 2013 (JUR 2014\60689).

${ }^{61}$ En opinión de DIEZ PICAZO, Luis; ex artículo 1727 CC toda ratificación puede hacerse en modo expreso o tácito, lo que implica que la ratificación tácita juegue también en la aplicación del artículo 1892 CC, en $L a$ representación en el Derecho Privado, Civitas, Madrid, 1979, p. 226, también LASARTE, Carlos; en “Artículo 1892”, Comentarios del Código Civil...., ob.cit.p.1949 y 1950. Sin embargo, no es ésta la línea seguida por el TS que en sentencia de 14 de mayo de 1991 (RJ 1991\3672) con ocasión de la aplicación del artículo 1892 CC considera que éste prevé sólo la ratificación expresa ya que respecto a la tácita está implícita en el art. 1893 CC. Sigue este criterio SANTOS BRIZ, Jaime; “Artículo 1892 y 1893” en Comentarios al Código Civil y Compilaciones Forales...., ob.cit.pp.62-68, Rivero HERnÁNDEZ, Francisco; Representación sin poder...ob.cit., p. 441. En nuestra opinión, la obligación ordenada en el art. 1893 CC es un caso de resarcimiento legal, impuesto ope legis al dueño al margen de su voluntad.
} 
aplicación del régimen normativo del mandato expreso pues de conformidad con el art. 622-40.2 CCC "El gestor está sujeto a las normas del contrato de mandato desde el momento de la ratificación de la gestión.” Lo que supone consecuencias importantes en el ámbito de la responsabilidad del gestor mandatario: será responsable si no ha actuado con la diligencia de un buen padre de familia (art. 1889 CC y art 622-41.1 y 622-42 CCC) y también en los supuestos de dolo o culpa (art. 1726 CC) pero no lo será en el caso fortuito dada la inaplicación del art. 1891 CC y 622-41.4 CCC que prevé para la gestión de negocios ajena que el gestor que acometa operaciones arriesgadas asuma su responsabilidad incluso en el caso fortuito. Además, al tratarse de una ratificación que implica la aceptación de las actuaciones del gestor, se exceptúa su posible responsabilidad por actuación extralimitada sin perjuicio de los derechos de los terceros de buena fe (art. 1725 CC y art. 622-22 CCC).

En suma, para llegar a una conclusión u otra deberán ser analizadas las circunstancias en que se produzca el silencio y valorar especialmente si han existido anteriores relaciones entre las mismas personas con el mismo contenido y si el modo de proceder implica el deber de hablar y cuáles son los usos generales del tráfico y los individuales de las partes $^{62}$.

\section{El conocimiento y prohibición de la gestión por el dueño.}

Cuando el titular conozca y manifieste su oposición o prohibición, no estaremos ante una gestión realizada con “motivo razonable” y, por lo tanto, no serán aplicables las reglas de la gestión de asuntos ajenos ${ }^{63}$. Salvo que la no intervención del gestor suponga un incumplimiento de una obligación de interés general en cuyo caso, como ya hemos estudiado, la gestión se entiende realizada con motivo razonable pese a la oposición del dueño $0^{64}$.

En consecuencia, el gestor que actúa en contra de la voluntad del dueño podrá reclamar sólo lo obtenido por éste en virtud del principio de enriquecimiento injusto: "El gestor, si su pretensión no se ajusta a los requisitos de la gestión de asuntos ajenos, puede recurrir a las reglas del enriquecimiento injustificado" (art. 622-42. 4) ${ }^{65}$. El dominus sólo quedaría obligado a devolver lo obtenido como consecuencia de la gestión en virtud de las reglas que regulan el enriquecimiento injusto.

Cuestión diferente es la relativa a aquellos casos en los que pese a que la gestión es calificada como oficiosa (realizada con motivo razonable) bien porque no se puede contactar con el titular y no puede ser postpuesta o bien porque pese a la oposición del titular se realiza en cumplimiento de un interés general, el titular no ratifica la gestión, porque no tiene interés en aprovechar su resultado o porque no se ha obtenido resultado

\footnotetext{
${ }^{62}$ En este sentido SÁNCHEZ JoRdÁN, María Elena; La gestión...., ob.cit. p. 262.

${ }^{63}$ Así la sentencia del TS de 20 de febrero de 1932 (RJ 917 1932 ) en Repertorio de Jurisprudencia, Aranzadi, T.II, Vol I, (años 1932-1933), rechaza la reclamación en calidad de gestor del arrendatario cuyo contrato había terminado y que había sido lanzado de la finca: la gestión de negocios nunca puede nacer de la usurpación.

${ }^{64}$ Ver ut supra epígrafe 3.2.2.3.

${ }^{65}$ Ver SANTos Briz, Jaime; “artículo 1888” en Albaladejo, Manuel (Dir); Comentarios, ob.cit. p. 55.
} 
alguno. El CCC establece de forma expresa que en estos supuestos el dueño pese a su oposición estará igualmente obligado a resarcir al gestor los gastos útiles y necesarios efectuados en su interés e indemnizarle por los daños y perjuicios que haya podido sufrir: "El titular del asunto, aunque no quiera aprovechar el resultado de la gestión o aunque no se haya obtenido ningún resultado está obligado a: a) Resarcir al gestor de los gastos útiles y necesarios efectuados en su interés. Las cantidades anticipadas por el gestor devengan interés legal desde el día del pago. b) Indemnizar al gestor por los daños y perjuicios. c) Liberar al gestor de las obligaciones contraídas en su interés" (art. 622-42.1 CCC).

\section{Bibliografía}

Ferran BADOSA Coll (1987), La Diligencia y la culpa del deudor en la obligación civil, Bolonia.

Ferran BADOSA COLL (2012), "El enriquecimiento injustificado. La formación de su concepto” en Bosch CAPDEVILA, Esteve (Dir.); Nuevas perspectivas del Derecho contractual europeo; Bosch; Barcelona, 2012, págs. 71-136.

Emilio BetTi (1959), Teoría General de negocio jurídico, Editorial Revista de Derecho Privado, Madrid.

Manuel CUADRADO IgLESIAS (2015), "Configuración, fundamento y naturaleza de la gestión oficiosa de negocios ajenos” en CUADRADO Iglesias, Manuel/NúÑEz BoludA, María de los Desamparados (Dir.), Estudios Jurídicos en Homenaje al profesor Manuel García Amigo, T.I, La Ley, Madrid, págs. 709-738.

Paloma DE BARRÓn ARNiCHES (2018), "Gestión de asuntos ajenos sin mandato. Breve apunte sobre los problemas prácticos que se derivan de la nueva regulación” en SERRANO DE NICOLÁs, Ángel (Coord.); Estudios sobre el Libro Sexto del Código Civil de Cataluña, Colegio Notarial de Cataluña/Marcial Pons, Madrid, págs. 365-382.

Federico De Castro y Bravo (1985), El negocio jurídico, Civitas, Madrid.

Pedro Del Pozo Carrascosa, Antoni Vaquer Aloy, Antoni Bosch CapdeVila (2018), Derecho Civil de Cataluña. Derecho de obligaciones y contratos, Marcial Pons, Madrid-Barcelona.

Luis Diez PiCAzo (1993), Fundamentos de Derecho civil patrimonial, T.II, $4^{\text {a }}$ Edición, Civitas, Madrid.

Luis Diez PiCAzo (1970), Fundamentos de Derecho Civil Patrimonial, T.I, Tecnos, Madrid.

Luis Diez Picazo (1991); Comentario del Código Civil, Tomo II, Ministerio de Justicia, Madrid, págs. 1944 y ss.

Salvador Durany Pich (2014), “Art. 237-11” en EgEA I FernÁNDEZ, Joan/Ferrer i Riba; Josep; Comentari al llibre segon del Codi Civil de Catalunya, Atelier, Barcelona, págs.1022-1025. 
Ludwig EnNeCCERus/Heinrich LeHMAnN (1966), Tratado de Derecho civil. Derecho de obligaciones. T.II, vol $2^{\circ}$, trad. y anotado por BlAS PÉREZ GONZÁLEZ y AlGUER, José, $3^{\text {a }}$ Edición, Bosch, Barcelona.

Sigfrifo FERRAR (1962), Gestione di affari altrui e rappresentanza, Giuffrè Editore, Milán.

Ildefonso L. Garcia Del CorRal (1897), Ildefonso L.; Cuerpo del Derecho Civil Romano, T.III, Barcelona, reimpresión en Lex Nova, Valladolid, 2004.

Florencio Garcia GoYena (1974), Concordancias, motivos y comentarios del Código Civil Español, Editorial Cometa, Zaragoza.

Carmen Jerez Delgado(Coord), (2015) Principios, definiciones y reglas de un Derecho Civil europeo: el Marco Común de Referencia (DCFR), Agencia estatal Boletín Oficial del Estado, Madrid.

José Luís LACRUZ BERDEJO/ Francisco de Asís SANCHO RebULLIDA (1979), Elementos de Derecho Civil, T.II, Vol. II, Edición Bosch Barcelona.

José Luís LACRUZ BERDEjo (1975), "La gestión de negocios sin mandato", en Revista Critica de Derecho Inmobiliario, núm. 507, marzo-abril, págs.245-270.

Albert LAMARCA MARQuÈs (2013), Código Civil alemán, Marcial Pons, Madrid.

Carlos Lasarte (1991), “Art. 1894” en Comentario del Código Civil, T.II, Ministerio de Justicia, Madrid, págs. 1953 y ss.

Florian LOYAL (2019) Die „entgeltliche“ Geschäftsführung ohne Auftrag: Grundlagen und Grenzen eines außervertraglichen Leistungsaustauschs, Mohr Siebeck; Tübingen.

Juana MARCo Molina (2014), "La gestión oficiosa de negocios ajenos: el nacimiento autónomo de las obligaciones del gestor y "dominus" o titular del asunto gestionado" en AAVV, Estudios Jurídicos en Homenaje al Profesor José María Miquel, Vol. 1, Thomson Reuters Aranzadi, Navarra, págs. 1817-1833.

Juana MARCo Molina (2015), “L’enriquiment injustificat. Proposta de regulació per al futur Llibre sisè del Codi Civil de Catalunya”, Revista Catalana de Dret Privat, vol 15-1, págs. 19-48.

Jacques MarTin De LA Moute(1951), L'acte juridique unilateral, Essai sur sa notion et sa technique en Droit Civil, Bernard Ferères, Paris.

Johannes MEIER (2019) Das subjektive System der Geschäftsführung ohne Auftrag: Die §§ 677686 BGB im Lichte der zweigliedrigen subjektiven Theorie, Mohr Siebeck, Tübingen.

Juan Carlos MenÉNDEZ MATo (1999), “La oferta tácita del mandato” en Actualidad Civil, núm. 13, págs. 321-343.

Rafael NuÑEz Lagos (1961) Código Civil Comentado y concordado extensamente, de Quintus Mucius Scaevola, T.XXX, vol. 2, (arts. 1887 a 1901), Reus, Madrid. 
Ma Ángeles PARRa LuCÁn (2014), “Los cuasicontratos” en MARTinez De AguirRe AldAz, Carlos; Curso de Derecho Civil II-Derecho de Obligaciones, Colex, Madrid, $4^{\text {a }}$ Ed.

Miguel PASQUAU LIAÑo (1986) La gestión de negocios ajenos, Montecorvo, Madrid.

Marcel Planiol, Jorge RiPERT (1945), Tratado práctico de Derecho civil francés, T.VII, Las obligaciones, $2^{\text {a }}$ Parte, Habana Cultural.

Federico PUig PeÑa (1972), Compendio de Derecho Civil Español, T. IV, Aranzadi, Pamplona.

Dieter ReuTER, (2006), J Von Staudinger, Kommentar zum Bürgerlichen Gesetzbuch mit Einführungsgesetz und Nebengesetzen, 2. Buch, Recht der Schuldverhältnisse §§ 657-704, 14., Sellier-de Gruyter, Berlin,

Francisco Rivero HERnÁNDEZ (2013), Representación sin poder y ratificación, Civitas Thomson, Navarra.

Ramón María Roca SASTRE, José PUIG BRUTAU (2009), "La gestión de negocios ajenos sin mandato" en Estudios de Derecho Privado, Thomson Reuters Aranzadi, Navarra.

María Elena SÁNCHEZ JoRDÁN (2000), La gestión de negocios ajenos, Civitas, Madrid, 2000.

María Elena SANCHEZ JORDÁN (2016) "De las obligaciones que se contraen sin convenio. Comentario al artículo 1888 CCE” en Cañizares Laso, A; De Pablo Contreras, P; Orduña Moreno, J; Valpuesta Fernandez; R (Dir), Código Civil comentado, vol. IV, $2^{\circ}$ Edición, Cizur Menor, Navarra, págs. 1310 y ss.

Ma Elena SÁnchez Jordán (2016), “Art- 1894” en CAÑizares LaSo, Ana/De Pablo Contreras, Pedro/Orduña Moreno, Javier/VAlpuesta Fernández, Rosario (Dir); Código Civil Comentado, Vol. IV, $2^{\text {a }}$ Edición, Thomson Reuters Civitas, Navarra, págs. 1333 y ss.

Felipe SÁnChEZ Román (1899), Estudios de Derecho Civil, Madrid, T.IV, Tipográfico Sucesores de Rivadeneyra, Madrid.

Jaime SANTOS BRIZ (1984), “artículo 1888” en ALBALADEJO, Manuel (Dir); Comentarios al Código Civil y Compilaciones Forales, T.XXIV; Edersa, Madrid, págs. 4 y ss.

Christian VON BAR (2006), Benevolent Intervenion in Anothers Affairs, Sellier European Law Publishers, Munich.

Christian Von Bar/ Eric Clive/ Hans Schulte-NölKe (2008) Principles, Definitions, Model Rules of European Private Law Draft Common Frame of Reference (DCFR), V, 1:101, Comments, Interim on line edition.

Carmen Vila Ribas (1995) “Gestión de negocios ajenos”, Enciclopedia Jurídica Básica, T.II, Civitas, Madrid, págs. 3244-3246. 